\title{
Short-term spatiotemporal variations in the aftershock sequence of the 2004 mid-Niigata prefecture earthquake
}

\author{
Aitaro Kato, Shinichi Sakai, Naoshi Hirata, Eiji Kurashimo, Satoru Nagai, Takashi Iidaka, Toshihiro Igarashi, \\ Yoshiko Yamanaka, Satoko Murotani, Tomonori Kawamura, Takaya Iwasaki, Toshihiko Kanazawa \\ Earthquake Research Institute, University of Tokyo, Tokyo 113-0032, Japan
}

(Received February 16, 2005; Revised May 13, 2005; Accepted May 27, 2005)

\begin{abstract}
We deployed 56 temporary seismic stations within approximately a month after the occurrence of the 2004 midNiigata prefecture earthquake. Using manually-picked arrival data obtained from the temporary and surrounding permanent seismic stations, 1056 aftershocks have been relocated. Based on the spatiotemporal variations in the relocated aftershocks, the cluster activities associated with the mainshock and some large aftershock events are identified. The aftershocks associated with the mainshock, the largest occurred on the two steep west-dipping planes at an angle of $60^{\circ}$ and approximately $5 \mathrm{~km}$ away. In contrast, the aftershocks following the event on Oct. 27 are aligned on east-dipping plane at a low angle of $25^{\circ}$. It is further observed that the aftershock area extended in both northeastward and southwestward directions at a later stage. The triggered seismicity around the northeast edge was more significant than that around the southwest edge. This difference could be understood by the discrepancy in the shear stress level accumulated at the dynamic shear rupture due to the mainshock.
\end{abstract}

Key words: Mid-Niigata prefecture earthquake, aftershocks, clusters.

\section{Introduction}

A shallow Mw 6.6 inland earthquake occurred in northwestern Japan (Niigata prefecture) on Oct. 23, 2004 and resulted in serious seismic damages including landslides in the surrounding areas. It is remarkable that the number of large aftershocks $(M>4)$ after this event is significantly greater than those after other large inland earthquakes [Japan Meteorological Agency (JMA) catalog] that have occurred recently in Japan. This sequence of aftershocks with magnitudes greater than 4 continued for approximately 2 weeks after the mainshock. The aftershock distributions have changed with time due to the triggered aftershocks of large magnitudes and finally resulted in highly complex patterns comprising of many earthquake clusters. An interaction between the earthquake clusters through stress transfer has the potential to develop such complex aftershock distributions (e.g., Stein, 1999) associated with the crustal heterogeneity due to crustal stretching and folding around the source region (e.g., Sato, 1994; Kato et al., 2005). Although the focal mechanisms of the mainshock and the large aftershocks show a reverse fault type with a strike of approximately N35E (Fig. 1, F-net), it is extremely difficult to determine even the fault dips of large events using only the data obtained by the permanent seismic stations (Sakai et al., 2005). Since the accurate aftershock distributions are significant for understanding the earthquake interaction through stress transfer and crustal heterogeneity, determining the hypocenter locations within dense seismic network is critical.

Copy right(c) The Society of Geomagnetism and Earth, Planetary and Space Sciences (SGEPSS); The Seismological Society of Japan; The Volcanological Society of Japan; The Geodetic Society of Japan; The Japanese Society for Planetary Sciences; TERRAPUB.
In order to investigate the accurate aftershock distributions and the development of the sequence of aftershocks, we deployed 56 temporary seismic stations for approximately one month in and around the source region of the mainshock. In this paper, the hypocenters for 1056 events with a magnitude greater than 2.2 , selected from the JMA catalog, are determined using the manually-picked traveltime data obtained by the temporary and surrounding permanent seismic stations. Further, the temporal- and spatialdistributions of the aftershocks for a period of approximately one month in and around the source region have been discussed. The details of the seismic activity within the first 5 days, which were determined by 14 temporary stations deployed immediately after the occurrence of the mainshock, are presented in another paper (Sakai et al., 2005).

\section{Data and Methods}

Figure 1 shows the map of seismic stations and the epicenters of relocated aftershocks in this study. The seismic network consists of 56 temporary stations with 3 components and 28 permanent stations located within $70 \mathrm{~km}$ from the center of the source region. Each temporary seismic station was equipped with $1-\mathrm{Hz}$ seismometer, signals of which were recorded continuously at a sampling rate of $100 \mathrm{~Hz}$, and a GPS receiver to maintain the accuracy of an internal clock with an order of $1 \mathrm{~ms}$. The temporary seismic stations were installed between Oct. 24 and Nov. 8, and the observations were carried out until Nov. 25. The heavy landslides fractured the roads to make it difficult to gain access to some of the areas close to the epicenter of the mainshock; hence, 4 seismic stations in those areas were installed using a helicopter (denoted by stars in Fig. 1). 
Table 1. Locations and station corrections of the temporary seismic stations used in the present studies for $P$ - and $S$-waves. Note that the station correction depends on two 1D velocity structures.

\begin{tabular}{|c|c|c|c|c|c|}
\hline \multicolumn{6}{|c|}{ For low veclotity structure (WEST side) } \\
\hline Station & Latitude & Lognitude & $\operatorname{ELV}(\mathrm{m})$ & $P(\mathrm{~s})$ & $S(\mathrm{~s})$ \\
\hline ST03.L8 & 37.3186 & 138.8257 & 50 & -0.3 & -0.48 \\
\hline ST05B.L8 & 37.2798 & 138.7911 & 100 & -0.54 & -1.07 \\
\hline ST05.L8 & 37.2914 & 138.8383 & 125 & -0.25 & -0.39 \\
\hline ST16.L8 & 37.415 & 138.9065 & 115 & 0.01 & 0.23 \\
\hline ST18.L8 & 37.4054 & 139.0129 & 355 & 0.16 & 0.36 \\
\hline ST19B.L8 & 37.3501 & 138.8387 & 65 & -0.14 & -0.14 \\
\hline ST19.L8 & 37.3711 & 138.8699 & 95 & -0.01 & 0.17 \\
\hline ST20.L8 & 37.3861 & 138.9961 & 285 & 0.14 & 0.3 \\
\hline ST25.L8 & 37.4261 & 139.0017 & 260 & 0.11 & 0.21 \\
\hline ST01.D & 37.3532 & 138.93 & 384 & 0.26 & 0.61 \\
\hline ST02.D1 & 37.3588 & 138.9469 & 337 & 0.24 & 0.69 \\
\hline ST03.D & 37.3186 & 138.8257 & 50 & -0.22 & -0.38 \\
\hline ST04.D & 37.3289 & 138.9521 & 270 & 0.24 & 0.68 \\
\hline ST05B.D & 37.2799 & 138.7911 & 101 & -0.46 & -0.95 \\
\hline ST05.D & 37.2912 & 138.8384 & 126 & -0.18 & -0.28 \\
\hline ST06.D1 & 37.2765 & 138.908 & 100 & -0.09 & -0.11 \\
\hline ST06.D2 & 37.2765 & 138.908 & 100 & -0.03 & 0.01 \\
\hline ST07.D & 37.3149 & 138.9767 & 300 & 0.35 & 0.93 \\
\hline ST08.D & 37.2788 & 138.9527 & 232 & 0.16 & 0.39 \\
\hline ST09.D & 37.2524 & 138.8321 & 66 & -0.26 & -0.3 \\
\hline ST10.D & 37.2517 & 138.9123 & 76 & -0.17 & -0.27 \\
\hline ST11.D & 37.2168 & 138.815 & 208 & -0.35 & -0.52 \\
\hline ST12.D & 37.1957 & 138.8687 & 185 & -0.2 & -0.32 \\
\hline ST13.D & 37.2183 & 138.8951 & 133 & -0.17 & -0.25 \\
\hline ST14.D & 37.1744 & 138.794 & 132 & -0.4 & -0.6 \\
\hline ST15.D & 37.1892 & 138.8361 & 272 & -0.36 & -0.57 \\
\hline ST16.DC & 37.4195 & 138.9018 & 110 & 0.03 & 0.09 \\
\hline ST17.D & 37.4141 & 138.8692 & 62 & -0.05 & -0.11 \\
\hline ST18.D & 37.4054 & 139.0129 & 353 & 0.18 & 0.38 \\
\hline ST19B.D & 37.3502 & 138.839 & 63 & -0.07 & -0.07 \\
\hline ST19.D & 37.3712 & 138.8699 & 96 & 0.05 & 0.29 \\
\hline ST20.DC & 37.3874 & 138.995 & 253 & 0.2 & 0.4 \\
\hline ST24.D & 37.2481 & 138.9615 & 131 & 0.23 & 0.63 \\
\hline ST25.D & 37.426 & 139.0017 & 258 & 0.14 & 0.25 \\
\hline ST26.D & 37.2238 & 138.7526 & 229 & -0.46 & -0.82 \\
\hline ST27.D & 37.1405 & 138.8297 & 330 & -0.24 & -0.34 \\
\hline ST46.D & 37.4345 & 139.0549 & 286 & 0.23 & 0.74 \\
\hline ST47.D & 37.4861 & 139.0945 & 160 & 0.11 & 0.34 \\
\hline ST47.DC & 37.5325 & 139.0962 & 102 & 0.22 & 0.58 \\
\hline ST48.D & 37.4925 & 138.929 & 22 & -0.3 & -0.74 \\
\hline ST49.D & 37.4686 & 138.769 & 36 & -0.38 & -0.69 \\
\hline ST50.D & 37.5003 & 139.0239 & 70 & 0.15 & 0.35 \\
\hline $\mathrm{ST}-28$ & 37.3559 & 138.6094 & 10 & -0.67 & -1.34 \\
\hline ST -29 & 37.3406 & 138.6487 & 29 & -0.73 & -1.34 \\
\hline $\mathrm{ST}-30$ & 37.3199 & 138.6766 & 146 & -0.64 & -0.89 \\
\hline ST-31 & 37.3058 & 138.7706 & 103 & -0.5 & -1.07 \\
\hline $\mathrm{ST}-32$ & 37.2892 & 138.7975 & 73 & -0.41 & -0.92 \\
\hline $\mathrm{ST}-33$ & 37.2342 & 138.9445 & 86 & 0.14 & 0.33 \\
\hline $\mathrm{ST}-38$ & 37.1719 & 138.8764 & 296 & 0.02 & 0.15 \\
\hline ST-38 & 37.1719 & 138.8764 & 296 & 0.01 & 0.16 \\
\hline $\mathrm{ST}-38$ & 37.1719 & 138.8764 & 296 & 0.01 & 0.18 \\
\hline H02.D & 37.3519 & 138.9831 & 374 & 0.23 & 0.54 \\
\hline H03.D & 37.317 & 138.948 & 422 & 0.21 & 0.45 \\
\hline H04.D & 37.332 & 139.0036 & 507 & 0.31 & 0.58 \\
\hline H05.D & 37.3252 & 138.9142 & 295 & 0.03 & 0.04 \\
\hline
\end{tabular}

\begin{tabular}{lllccr}
\hline & \multicolumn{2}{l}{ For high velocity structure (EAST side) } & \\
Station & Latitude & Lognitude & ELV $(\mathrm{m})$ & $P(\mathrm{~s})$ & \multicolumn{1}{c}{$S(\mathrm{~s})$} \\
\hline S21C & 37.373 & 139.0898 & 440 & -0.43 & -0.54 \\
S22D & 37.3231 & 139.0271 & 182 & -0.38 & -0.37 \\
S23D & 37.2933 & 139.0184 & 219 & -0.35 & -0.29 \\
S43D & 37.2999 & 139.0549 & 218 & -0.33 & -0.21 \\
ST34 & 37.2238 & 139.0109 & 158 & -0.39 & -0.33 \\
ST35 & 37.2056 & 139.0595 & 218 & -0.34 & -0.21 \\
ST36 & 37.1868 & 139.0867 & 290 & -0.26 & -0.08 \\
ST37 & 37.1759 & 139.1282 & 759 & -0.1 & 0.22 \\
ST39 & 37.1121 & 138.9248 & 146 & -0.49 & -0.51 \\
\hline
\end{tabular}

Table 2. Locations and station corrections of the permanent seismic stations used in the present studies for $P$ - and $S$ - waves.

\begin{tabular}{cccccc}
\hline \multicolumn{7}{c}{ For low veclotity structure (WEST side) } \\
Station & Latitude & Lognitude & ELV $(\mathrm{m})$ & $P(\mathrm{~s})$ & $S(\mathrm{~s})$ \\
\hline KZK & 37.2951 & 138.5157 & 220 & -0.1 & 0.2 \\
YHJ & 37.7336 & 138.8030 & 30 & 0.29 & 0.88 \\
TNN & 36.9423 & 138.5947 & 450 & 0.29 & 0.78 \\
KWNH & 37.1697 & 138.7472 & -40 & -0.56 & -0.85 \\
NGOH & 37.4242 & 138.8908 & -15 & -0.03 & 0.1 \\
MAKH & 37.0514 & 138.3997 & 130 & -0.18 & -0.08 \\
KMOH & 37.6497 & 139.0708 & -70 & -0.27 & -0.39 \\
MKOH & 36.9394 & 138.2625 & 130 & -0.26 & -0.39 \\
NZWH & 36.9072 & 138.4439 & 460 & 0.62 & 1.36 \\
IZUMOZ & 37.5317 & 138.7095 & 40 & -0.72 & -1.34 \\
NAKAMA & 37.1030 & 138.1630 & 140 & 0.25 & 0.49 \\
SASAKA & 37.8183 & 139.3172 & 145 & 1.04 & 2.38
\end{tabular}

\begin{tabular}{cccccr}
\hline \multicolumn{7}{c}{ For high velocity structure (EAST side) } \\
Station & Latitude & Lognitude & ELV $(\mathrm{m})$ & \multicolumn{1}{c}{$P(\mathrm{~s})$} & \multicolumn{1}{c}{$S(\mathrm{~s})$} \\
\hline HRG & 37.2371 & 139.0362 & 210 & -0.34 & -0.19 \\
SEK & 37.0884 & 139.4914 & 705 & -0.09 & 0.72 \\
HIROKA & 37.2483 & 139.0170 & 195 & -0.36 & -0.29 \\
KNY & 37.4001 & 139.5588 & 390 & -0.16 & 0.51 \\
YNTH & 37.2208 & 138.9853 & 0 & -0.49 & -0.42 \\
STDH & 37.5356 & 139.1311 & -7 & -0.71 & -0.74 \\
MUIH & 37.0503 & 138.9983 & 258 & -0.29 & -0.03 \\
SZWH & 37.0272 & 138.8553 & -202 & -0.56 & -0.55 \\
TDMH & 37.3392 & 139.3179 & 175 & -0.42 & -0.06 \\
MNKH & 36.8384 & 139.0588 & 772 & 0.01 & 0.64 \\
YZWH & 36.8083 & 138.7881 & 885 & 0.12 & 0.77 \\
INAH & 37.1692 & 139.5231 & 472 & -0.25 & 0.53 \\
KMKH & 37.5408 & 139.3681 & 118 & -0.42 & -0.04 \\
KYWH & 36.8786 & 139.4567 & 985 & 0.14 & 1.15 \\
TWAH & 37.6678 & 139.4681 & -232 & -0.63 & -0.27 \\
MRMH & 37.6628 & 139.2642 & -32 & -0.32 & 0.02 \\
\hline
\end{tabular}

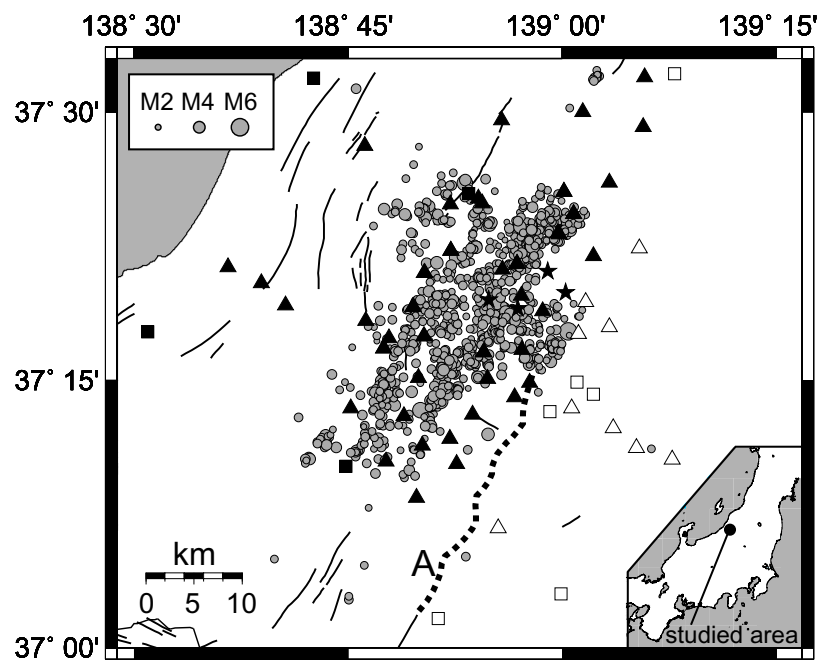

Fig. 1. Relocated aftershocks and station distributions. Triangles and squares show the temporary seismic stations and permanent stations. Starts denote the stations installed using the helicopter. The solid and open symbols correspond to the station of which velocity structure adopted in hypocenter location is low and high velocity structure, respectively. Relocated epicenters in the present study are shown by gray circles scaled to the earthquake magnitude. The Muikamachi fault (A) is shown by thick broken line, and the other major active faults are shown by thin solid lines. 
(b)

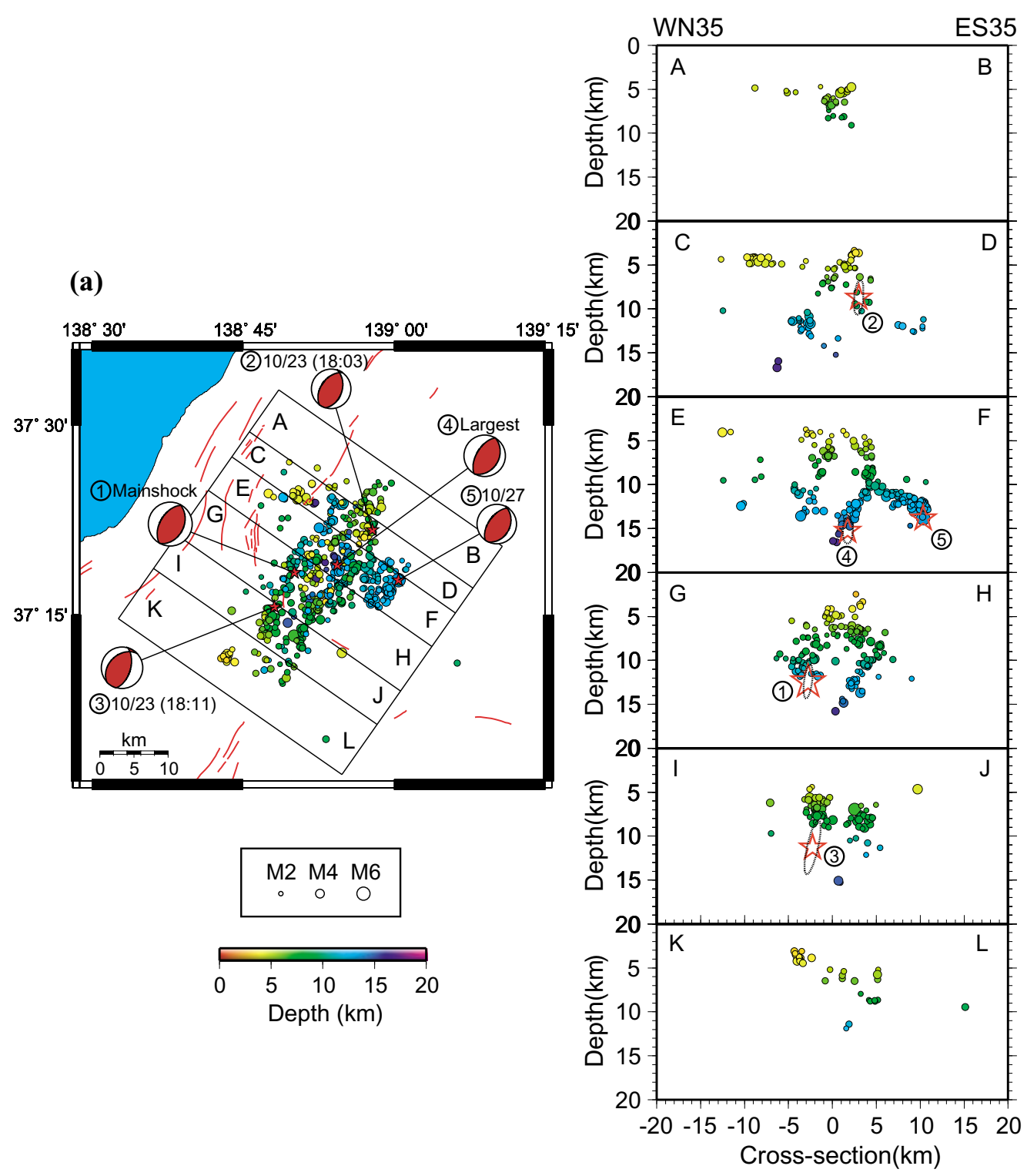

Fig. 2. Relocated aftershock distributions from $1800 \mathrm{~h}$ Oct. 24 to Oct. 28, 2004. Five red stars denote the hypocenters of (1) the mainshock, (4) the largest aftershock (1834 h Oct. 23), two large aftershocks (2) $1803 \mathrm{~h}$ and (3) $1811 \mathrm{~h}$, Oct. 23) and (5) the Mw=5.8 aftershock (Oct. 27), respectively, with the moment tensor from NIED. (a) Epicenter distributions. (b) The depth section for each box shown in Fig. 2(a). The strike of the cross section is $55^{\circ}$ from north to west, which is selected to be perpendicular to the direction of the geological structure in this region. The sizes and colors of the circles are scaled to the magnitude, and the depth, respectively. The error ellipsoids $(2 \sigma)$ for four large events on Oct. 23 are shown by broken curves.

We selected the hypocenters of the 1056 aftershocks with a magnitude greater than 2.2 that occurred at 1800 on Oct. 24 to Nov. 26 from the JMA catalog. Both $P$ - and $S$-wave arrival times for these events were picked manually from all the stations mentioned in this paper. Next, a maximum likelihood estimation algorithm for hypocenter location (Hirata and Matsu'ura, 1987) was applied to the arrival data. Since the crustal velocity structure changes laterally around the source region (Takeda et al., 2004; Kato et al., 2005), the hypocenter locations are determined assuming two different one-dimensional velocity structures in the northwestern and southeastern directions of the source region. The boundary between these velocity structures roughly coincides with that of the Muikamachi fault (Fig. 1) and its northeastward extension. At shallow depths of less than $3 \mathrm{~km}$, the north- western side of the Muikamachi fault has a significant low velocity, while the southeastern side has a moderately high velocity (see figure 2 in Sakai et al., 2005). Further, the station correction for each seismic station has been evaluated using the average of the travel time residual at each station. Then, we adopted the station corrections to locate the aftershocks (Tables 1 and 2).

In order to assess the reliability of the hypocenter calculations, we apply a statistical resampling approach to all events (bootstrap method; Shearer, 1997). For a final hypocenter, we calculated the synthetic arrival time data by randomly adding the noises with zero mean and a standard deviation of 0.09 s for $P$-wave and 0.2 s for $S$-wave, which conform to the observed residual distributions for $P$ - and $S$-waves, to the observed arrival time data. We then re- 
(b)

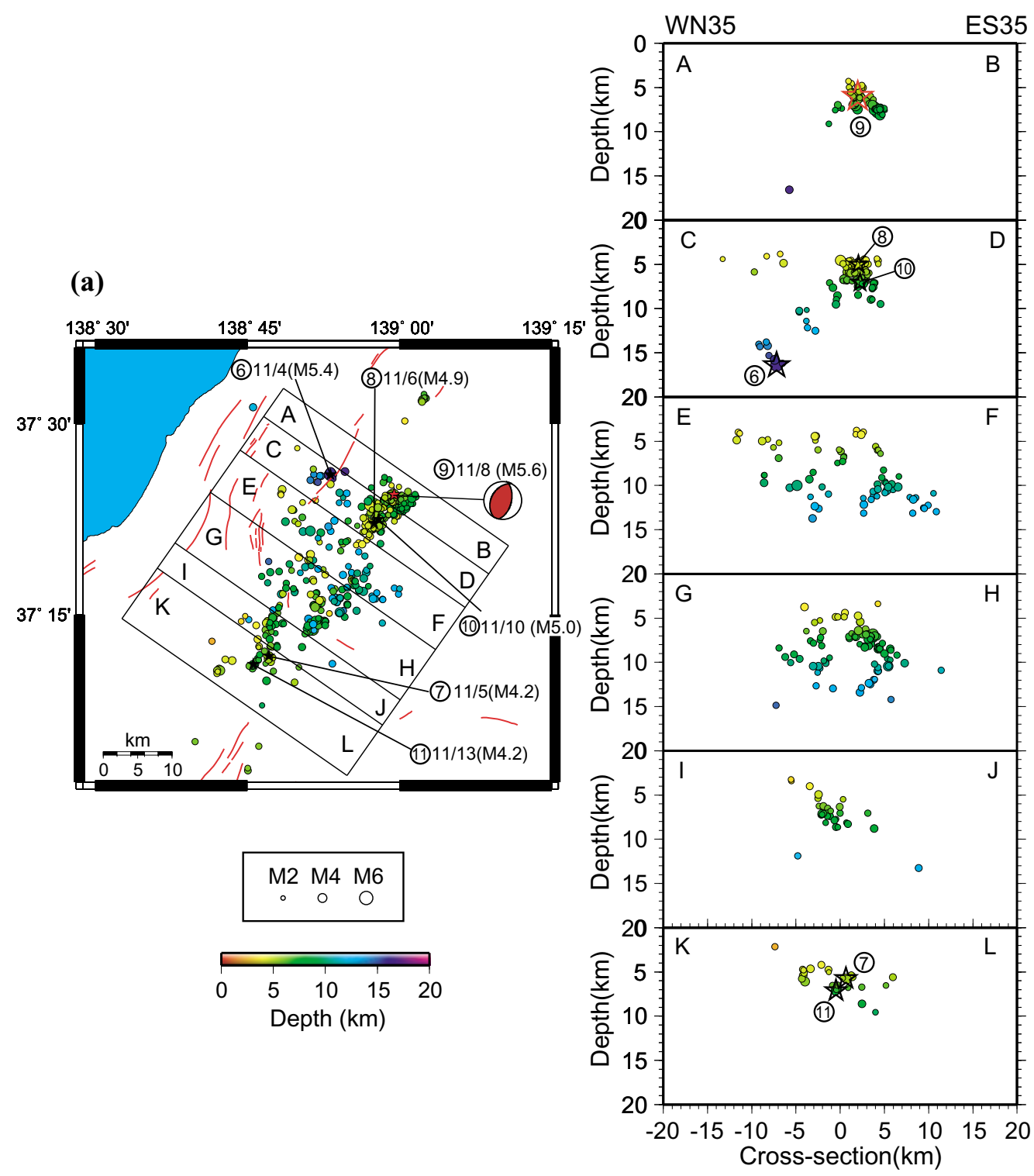

Fig. 3. Relocated aftershock distributions from Oct. 29 to Nov. 26, 2004. A red star denotes the hypocenter of the large aftershock (Nov. 8, (9)) with the moment tensor from NIED. Moderate aftershocks at the edge of the source region are shown by black stars with numbers. (a) Epicenter distributions. (b) The depth section for each box shown in Fig. 3(a). The sizes and colors of the circles are scaled to the magnitude, and the depth, respectively.

located all the events using these resampled data to determine the shift in the locations from the final hypocenter. The process was repeated 200 times for each event. We calculated a mean and a variance-covariance matrix of the synthetic hypocenters to evaluate a hypocenter and its uncertainty. The location error is defined as $2 \sigma$ ( $\sigma$ : standard deviation for the amount of the shifts) for each direction, which contains almost $95 \%$ of the relocated events with resampled data. Estimated uncertainties in the horizontal and vertical directions are averaged to 0.4 and $0.8 \mathrm{~km}$, respectively. However, the vertical uncertainties in the southwest of the source region were twice of that in the other areas considered until Oct. 27, since the enough temporary seismic stations had not been installed by then.

Because the large events with magnitude larger than 6 occurred on Oct. 23 before the temporary seismic stations were deployed, we relocated their hypocenters using the travel time data observed at the surrounding permanent stations (Sakai et al., 2005). In relocating the hypocenter of the event at 1811 on Oct. 23 , a $P$-wave arrival time data observed at the KIK-NET station of Kawanishi [NIED] was added. With regard to the location errors for 4 large events on Oct. $23(M>6)$, the estimated uncertainties in the horizontal and vertical directions ranged from 0.5 to $1 \mathrm{~km}$ and from 1.5 to $3 \mathrm{~km}$, respectively (Fig. 2). It should be noted that the absolute accuracies for the mainshock and the large aftershocks are worse than those of the aftershocks relocated using the temporary seismic station data presented in this paper, because of no stations just above these events.

\section{Aftershock Distributions}

Figure 2 shows the distributions of the relocated aftershocks that occurred until Oct. 28. From Fig. 2, it can be observed that the aftershocks associated with the mainshock 
(1) and the largest aftershock (at 1834, Oct. 23, (4)) occurred on the 2 west-dipping planes at an angle of $60^{\circ}$ and approximately $5 \mathrm{~km}$ apart (Fig. 2, G-H, E-F); on the other hand, the aftershocks on Oct. 27 (5) are aligned on the east-dipping plane at a low angle of $25^{\circ}$, which is a conjugate of the main fault. It should be noted that the hypocenters of three large events are located at the deepest part of each aftershock plane, which implies that the shear rupture is initiated at the deepest part of the fault. The aftershocks associated with the event at 1803 on Oct. 23 (2) seem to be distributed around the east-dipping plane (Fig. 2, C-D). However, the trend is not clear due to a small number of aftershock activities with a magnitude greater than 2.2. Indeed, Sakai et al. (2005) delineated the aftershock distribution aligned on the eastward dipping plane, using the small events with magnitude less than 2.2. Further, the aftershocks associated with the event at 1811 on Oct. 23 (3)) appear to occur on the east-dipping planes with a steep dip angle of approximately $53^{\circ}$ (Fig. 2 I-J). Although a depth of the event at 1811 is poorly constrained $( \pm 3.0 \mathrm{~km})$ due to the lack of the travel time data near the hypocenter, the cluster on the northwest side is considered to correspond to the aftershock activities associated with the event.

The relocated aftershock distributions after Oct. 29 are shown in Fig. 3. It is clear that the prominent cluster activities are located around the northeastern edge of the aftershock region (Fig. 4). Those activities were triggered by a sequence of the large or moderate events that occurred on Nov. 6 (M4.9; (8), Nov. 8 (M5.6; (9) and Nov. 10 (M5.0; (10) around the northeastern edge. It should be noted that the aftershocks triggered by the event on Nov. 8 result in an east-dipping plane at an angle of approximately $45^{\circ}$ (Fig. 3, A-B), which is steeper than the planes of the large aftershocks on Oct. 27 at an angle of approximately $25^{\circ}$ (Fig. 2, E-F). These differences in the fault dip angles for the events between Nov. 8 and Oct. 27 coincide with the variations in the dip angle of the focal mechanism plane for each event, estimated by F-net (Fig. 2, 3) [the National Research Institute for Earth Science and Disaster Prevention]. The hypocenter depths associated with the events on Nov. 6,8 , and 10 are restricted to shallow depths. Further, the northward extension of the aftershock activities is observed at a greater depth of approximately $16 \mathrm{~km}$, where the event of magnitude 5.4 (6) occurred on Nov. 4 (Fig. 3, C-D), and these aftershocks are aligned on the steep east-dipping planes.

Figure 3 also shows that the aftershock area extends southwestward. This activity was triggered by the occurrence of the two aftershocks with a magnitude of 4.2 at a depth of approximately $7 \mathrm{~km}$ that occurred on Nov. 5 (7) and Nov. 13 (11) (Fig. 3, K-L). Note that the aftershock activity around the southwestern edge is not higher than that around the northeastern edge of the source region.

\section{Discussions}

From the depth sections of the aftershock distributions (Figs. 2, 3) and the elapsed time and space history (Fig. 4), the complex hypocenter distributions associated with many aftershock activities have been identified and formed the east- or west-dipping planes. The fault dips for major

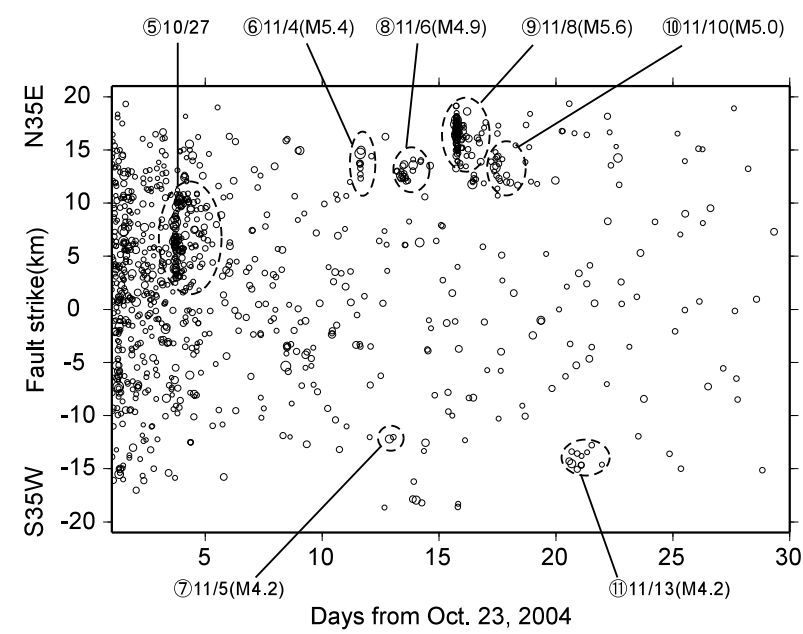

Fig. 4. Elapsed time-space plot of the relocated epicenters projected to the fault strike. The origin of the vertical axis corresponds to the epicenter of the mainshock.

events, such as the mainshock, the largest aftershock, and the aftershock on Oct. 27, are consistent with those estimated by other studies (Okada et al., 2005; Shibutani et al., 2005). Based on the seismic tomographic studies (Kato et al., 2005; Okada et al., 2005), the aftershock distributions associated with these major events are located at the boundary between low and high velocity structures. It is interpreted that the mainshock fault plane of the mid-Niigata prefecture earthquake was reactivated as a reverse fault due to the crustal shortening initiated at $3.5 \mathrm{Ma}$ (Hirata et al., 2005; Kato et al., 2005; Okada et al., 2005; Sato and Kato, 2005). Thus, it is suggested that the complex distributions of aftershock activities are potentially caused by the heterogeneous geological structures, which might be formed during the crustal stretching or shortening along the coastline of Japan.

From the temporary GPS observations, Takahashi et al. (2005) have estimated that the fault plane of the Nov. 8 event can be dipping westward. However, it appears to be difficult to determine whether the fault plane dip is westward or eastward, since there were no GPS observation data for the plane above the estimated fault plane. Nevertheless, this study shows that the aftershock activities are aligned on the east-dipping plane at the northeast cross section where the hypocenter of the Nov. 8 event is located (Fig. 3, A-B). Since we recorded the seismograms at 3 temporary seismic stations that are located at an epicentral distance of less than $2 \mathrm{~km}$, we have enough accuracy in locations of those events; spatial errors of less than $0.2 \mathrm{~km}$ in the horizontal direction and those of less than $0.4 \mathrm{~km}$ in the depth.

From Fig. 4, it is noted that the aftershock activities associated with the mainshock and large aftershocks have continued till the end of November and the generation rate decreased with the elapsed time. In contrast, northeast- and southwest-ward extension of the aftershock activity became prominent at a later stage (Figs. 3, 4). The spatial extension of the aftershock activities has also been observed in other inland earthquakes (e.g., the 2000 Western Tottori Earthquake (Fukuyama et al., 2003) and the 2003 Northern 
Miyagi earthquake (Okada et al., 2003)).

The activities triggered by the Nov. 8 event (M5.6) around the northeast edge are particularly significant. The reason behind high seismicity around the northeast edge is believed to be the accumulated shear stress subjected in the region due to the mainshock rupture before the event. The waveform inversion study on the mainshock rupture process revealed that the large fault slip was generated both around the hypocenter and at the shallow northeast area of the hypocenter, and the shear rupture propagated toward northeastern side of the source region (Honda et al., 2005). Thus, the large fault slip at the shallow northeast area increased the shear stress around the northeast edge of the aftershock area. The aftershock activity near the northeast region was observed before Nov. 8 (Fig. 4), and the seismicity rate was higher than usual. Based on a stress transfer model that incorporates the frictional constitutive law (Toda and Stein, 2003), the triggered seismicity rate increased remarkably when further shear stress is built up in such a region where the seismicity rate has already been high.

\section{Conclusions}

Dense seismic observations were conducted for a period of approximately 1 month after the occurrence of the 2004 mid-Niigata prefecture earthquake. Based on the spatiotemporal variations in the relocated aftershock distributions, the cluster activities associated with some large aftershock events were identified. It is further observed that the aftershock area extended in the northeastward and southwestward directions and the east- or west-dipping planes were formed associated with this extension of the aftershock area at the later stage. The triggered seismicity around the northeast edge was more significant than that around the southwest edge.

Acknowledgments. We are grateful to K. Doi, T. Yasuda, I. Ogino, H. Hagiwara, M. Saka, M. Serizawa, Y. Hirata, M. Kobayashi, T. Haneda, S. Watanabe for data acquisition. We are thankful to Prof. Y. Iio and an anonymous reviewer for their constructive comments, which led to substantial improvement in the original manuscript. We thank to the National Research Institute for Earth Science and Disaster Prevention, Japan Meteorological Agency, and Tohoku University for allowing us to use the waveform data collected at each permanent station. Most of the figures were created using GMT (Wessel and Smith, 1995). This work was supported by the Grant-in-Aid for Special Purposes (16800054) and the Special Coordination Funds for the Promotion of Science and Technology offered by the Ministry of Education, Culture, Sports, Science and Technology of Japan (MEXT) under the title of Urgent Research for the 2004 Mid-Niigata Prefecture Earthquake, and a grant offered under the Earthquake Prediction Research program of MEXT.

\section{References}

Fukuyama, E., W. L. Ellsworth, F. Waldhaused, and A. Kubo, Detailed fault structure of the 2000 Western Tottori, Japan, Earthquake sequence, Bull. Seism. Soc. Am., 93, 1468-1478, 2003.

Hirata, N. and M. Matsu'ura, Maximum-likelihood estimation of hypocenter with origin time eliminated using nonlinear inversion technique, Phys. Earth Planet. Inter., 47, 50-61, 1987.
Hirata, N., H. Sato, S. Sakai, A. Kato, and E. Kurashimo, Fault system of the 2004 Mid Niigata Prefecture Earthquake and its aftershocks, Landslides, 2(2), 2005.

Honda, R., S. Aoi, N. Morikawa, H. Sekiguchi, T. Kunugi, and H. Fujiwara, Ground motion and rupture process of the 2004 Mid Niigata Prefecture earthquake obtained from strong motion data of K-NET and KiK-net, Earth Planets Space, 57, this issue, 527-532, 2005.

Kato, A., E. Kurashimo, N. Hirata, T. Iwasaki, and T. Kanazawa, Imaging the source region of the 2004 Mid-Niigata prefecture earthquake and the evolution of a seismogenic thrust-related fold, Geophys. Res. Lett., 32 , L07307, doi:10.1029/2005GL022366, 2005.

Kato, N., T. Echigo, H. Sato, M. Tateishi, S. Ogino, S. Sakai, S. Toda, S. Koshiya, T. Ito, T. Toyoshima, T. Imaizumi, H. Kato, and S. Abe, High resolution seismic reflection profiling across the surface rupture associated with the 2004 Mid-Niigata Prefecture earthquake (M6.8), central Japan, Earth Planets Space, 57, 447-452, 2005.

Okada, T., N. Umino, and A. Hasegawa, Rupture process of the July 2003 northern Miyagi earthquake sequence, NE Japan, estimated from double-difference hypocenter locations, Earth Planets Space, 55, 741$750,2003$.

Okada, T., N. Umino, T. Matsuzawa, J. Nakajima, N. Uchida, T. Nakayama, S. Hirahara, T. Sato, S. Hori, T. Kono, Y. Yabe, K. Ariyoshi, S. Gamage, J. Shimizu, J. Suganomata, S. Kita, S. Yui, M. Arao, S. Hondo, T. Mizukami, H. Tsushima, T. Yaginuma, A. Hasegawa, Y. Asano, H. Zhang, and C. Thurber, Aftershock distribution and 3D seismic velocity structure in and around the focal area of the $2004 \mathrm{mid}$ Niigata prefecture earthquake obtained by applying double-difference tomography to dense temporary seismic network data, Earth Planets Space, 57, 435-440, 2005.

Sakai, S., N. Hirata, A. Kato, E. Kurashimo, T. Iwasaki, and T. Kanazawa, Multi-fault system of the 2004 Mid-Niigata Prefecture Earthquake and its aftershocks, Earth Planets Space, 57, 417-422, 2005.

Sato, H., The relationship between late Cenozoic tectonic events and stress field and basin development in northeast Japan, J. Geophys. Res., 99, 22261-22274, 1994.

Sato, H. and N. Kato, Relationship between geologic structure and the source fault of the 2004 Mid Niigata Prefecture Earthquake, central Japan, Earth Planets Space, 57, 453-457, 2005.

Shearer, P., Improving local earthquake locations using the L1 norm and waveform cross correlation: application to the Whittier Narrows, California, aftershock sequence, J. Geophys. Res., 102, 8269-8283, 1997.

Shibutani, T., Y. Iio, S. Matsumoto, H. Katao, T. Matsushima, S. Ohmi, F. Takeuchi, K. Uehira, K. Nishigami, B. Enescu, I. Hirose, Y. Kano, Y. Kohno, M. Korenaga, Y. Mamada, M. Miyazawa, K. Tatsumi, T. Ueno, H. Wada, and Y. Yukutake, Aftershock distribution of the 2004 Mid Niigata Prefecture Earthquake derived from a combined analysis of temporary online observations and permanent observations, Earth Planets Space, 57, this issue, 545-549, 2005.

Stein, R. S., The role of stress transfer in earthquake occurrence, Nature, 402, 605-609, 1999.

Takahashi, H., T. Matsushima, T. Kato, A. Takeuchi, T. Yamaguchi, Y. Kohno, T. Katagi, J. Fukuda, K. Hatamoto, R. Doke, Y. Matsu'ura, and M. Kasahara, A fault model of an aftershock (M5.9) on November 8 and postseismic deformation of the 2004 Niigata Chuetsu earthquake (M6.8) by a dense GPS observation, Earth Planets Space, 2005 (submitted).

Takeda, T., H. Sato, T. Iwasaki, N. Matsuta, S. Sakai, T. Iidaka, and A. Kato, Crustal structure in the northern Fossa Magna region, central Japan, from refraction/wide-angle reflection data, Earth Planets Space, 56, 1293-1299, 2004.

Toda, S. and R. Stein, Toggling of seismicity by the 1997 Kagoshima earthquake couplet: A demonstration of timedependent stress transfer, J. Geophys. Res., 108(B12), 2567, doi:10.1029/2003JB002527, 2003.

Wessel, P. and W. H. F. Smith, New version of the generic mapping tools released, Eos Trans. AGU, 76, 329, 1995.

A. Kato (e-mail: akato@eri.u-tokyo.ac.jp), S. Sakai, N. Hirata, E. Kurashimo, S. Nagai, T. Iidaka, T. Igarashi, Y. Yamanaka, S. Murotani, T. Kawamura, T. Iwasaki, and T. Kanazawa 